\title{
Pemanfaatan Ecobricks Sebagai Media Pembelajaran Untuk Anak Usia Dini
}

\author{
Warananingtyas Palupi, Siti Wahyuningsih, Endang Widiyastuti, Novita Eka \\ Nurjanah, Adriani Rahma Pudyaningtyas \\ Universitas Sebelas Maret \\ e-mail: palupi_paud@staff.uns.ac.id
}

\begin{abstract}
Abstrak
Kegiatan bertujuan meningkatkan pengetahuan serta keterampilan guru-guru Taman Kanakkanak (TK) di Surakarta dalam memanfaatkan ecobricks sebagai media pembelajaran khususnya sebagai bahan dasar pembuatan alat permainan edukatif (APE). Ecobricks merupakan suatu bahan ramah lingkungan berasal dari botol-botol plastik bekas yang tidak dapat terurai. Kegiatan sejalan dengan banyaknya masalah berkaitan dengan sampah, yiatu: (1) Banyaknya jumlah sampah plastik ditemukan di lingkungan yang belum dimanfaatkan secara optimal, (2) Kurangnya pengetahuan dalam pengolahan dan pemanfaatan sampah plastik sebagai media pembelajaran ramah linkungan, (3) Karakter untuk mencintai lingkungan pada anak tidak akan terbentuk tanpa stimulasi dari guru. Berdasar pada latar belakang tersebut, kegiatan berfokus pada pemberian pelatihan kepada guru-guru untuk memanfaatkan ecobricks sebagai media pembelajaran melalui pembuatan APE ramah lingkungan. Metode pelatihan dilakukan melalui proses ceramah, tanya jawab, demonstrasi, serta praktek langsung pembuatan APE. Hasil yang diperoleh menujukkan terjadinya peningkatan pengetahuan dan keterampilan guru-guru dalam memanfaatkan sampah plastik dengan menggunakan ecobricks sebagai APE. Guru-guru dapat membagikan pengalaman yang telah diperoleh kepada anak dan orang tuanya.
\end{abstract}

Kata kunci: ecobricks, alat permainan edukatif (APE), guru-guru Taman Kanak-kanak (TK)

\section{PENDAHULUAN}

Sampah terutama sampah plastik saat ini merupakan salah satu masalah utama yang dihadapi oleh penduduk dunia. Beberapa negara seperti Jerman, Jepang, Belanda, dan Australia telah mampu melakukan daur ulang sampah sebanyak 52 s.d.

56 persen (Komp, 17 Mei 2018). Keberhasilan ini didukung oleh kebijakan pemerintah dan kesadaran masyarakatnya dalam mengelola sampah. Indonesia juga telah memulai upaya pengelolaan sampah sejak satu dekade lalu, tetapi belum menunjukkan hasil yang optimal.

Jambeck, dkk (2015) menyebutkan bahwa Indonesia menempati ranking kedua di dunia sebagai negara penghasil sampah plastik yang ada di laut, yaitu 187.2 juta ton. Data dari Asosiasi Industri Plastik Nasional (INAPLAS) dan Badan Pusat Statsitik (BPS) menunjukkan bahwa sampah plastik yang dihasilkan di Indonesia mencapai 64 juta tons per tahun. Sampah plastik yang dibuang di laut sebanyak 3.3 juta ton dan kantong plastik yang terbuang di lingkungan sebanyak 10 milyar lembar per tahun atau sebanyak 85.000 ton sampah kantong palstik. Plastik membutuhkan waktu sekitar 400 tahun untuk terurai (Amaral dalam Mohamed, dkk, 2017). Upaya yang dapat dilakukan untuk mengolah sampah-sampah tersebut adalah melalaui 3R, yaitu Reduce, Reuse, dan Recycle.

Permasalahan sampah juga dihadapi oleh guru-guru TK. Berdasar hasil observasi dan wawancara yang dilakukan, masalah yang dihadapi antara lain (1) Banyaknya jumlah sampah plastik yang ditemukan di lingkungan yang belum 
dimanfaatkan secara optimal, (2) Kurangnya pengetahuan dalam pengolahan dan pemanfaatan sampah plastik sebagai media pembelajaran yang ramah linkungan, (3) Karakter untuk mencintai lingkungan pada anak tidak akan terbentuk tanpa stimulasi dari guru. Upaya untuk mengatasi permasalah sebenarnya sudah dilakukan, antara lain dengan memanfaatkan sampah plastik untuk membuat kerajinan tangan seperti bunga, tas, baju, dll, tetapi upaya tersebut masih belum optimal untu mengurangi jumlah sampah plastik yang ada. Oleh karena itu, perlu upaya lain untuk mengatasi masalah sampah tersebut. Sakah satu upaya yang dapat dilakukan adalah melalui pemanfaatan ecobricks.

Ecobricks merupakan salah satu upaya daur ulang (recycle) untuk mengurangi jumlah sampah plastik. Ecobricks terbuat dari botol plastik bekas yang diisi oleh bahan-bahan seperti tanah, busa, plastik pembungkus makanan, kantong plastik, serta bahan-bahan plastik lainnya (Antico, dkk, 2018). Ecobricks biasanya terbuat dari botol plastik bekas yang diisi dengan plastik-plastik lain yang berukuran lebih kecil. Kamble dan Karad (2017) menyebutkan bahwa ecobricks dapat dimanfaatkan sebagai bahan bangunan. Ecobricks digunakan untuk membuat furniture, taman dan bangunan dalam skala besar seperti sekolah dan rumah. Ecobricks juga dapat digunakan untuk membuat karya seni. Karya seni ini mengusulkan konsep daur ulang dan ide-ide baru dalam membuat batu bata ramah lingkungan (ecobricks).

Lenkiewicz dan Webster (2017) menyatakan bahwa setiap orang dalam sebuah komunitas dapat bergabung membuat ecobricks termasuk anak-anak. Pembuatan ecobricks juga memungkinkan kolaborasi antara siswa, orang tua, guru dan staff di sekolah dalam menciptakan ruang hijau yang indah tanpa biaya yang mahal, seperti taman bermain dan taman. Kegiatan pembuatan ecobricks dapat juga dimasukkan ke dalam kurikulum (Maier \& Angway, 2015).

Manisha \& Singh (2017) menyebutkan manfaat membuat ecobricks antara lain 1) Pengelolaan limbah; membuat ecobriks adalah salah satu cara yang efisien untuk mengolah limbah plastik dan dapat dilakukan oleh semua orang karena pembuatannya yang mudah; 2) Melindungi lingkungan dengan mengurangi jumlah sampah plastik; 3) Membuat ecobricks yang digunakan sebagai bahan bangunan atau furniture dapat mengurangi biaya produksinya. Muyen, dkk. (2016) menyimpulkan bahwa ecobricks lebih murah daripada batu bata; 4) Inovasi terbaru ini dapat memberikan pengetahuan dan keterampilan baru sehingga ada peluang dalam mendapatkan pekerjaan. Goud, dkk. (2014) menyebutkan bahwa keterlibatan masyarakat lokal dalam proses pembuatan batu bata dan konstruksi bangunan akan meningkatkan keterampilan dan pengetahuan mereka untuk bekerja; 5) Furniture dan bangunan yang terbuat dari ecobricks tidak mudah rusak karena terbuat dari plastik yang akan terurai selama 300 tahun dan dapat digunakan kembali. Nitin dan Manisha (2016) menyatakan bahwa rumah yang terbuat dari ecobricks tidak mudah rapuh, dapat digunakan kembali, mudah dibangun dan ringan; 6) Raut, dkk. (2015) menyatakan bahwa ecobricks memiliki kemampuan konstruksi yang baik dan hemat biaya. Penggunaan ecobricks dalam pembuatan furniture dan bangunan memiliki daya tahan lebih lama karena bahan plastik yang digunakan tidak mudah terurai; 7) Mengurangi penggunaan semen atau kayu dalam konstruksi bangunan dan furniture akan mengurangi emisi $\mathrm{CO}_{2}$ selama produksi semen dan pemotongan kayu. Mojtaba, dkk. (2013) mengatakan bahwa batu bata dari botol plastik dapat membantu melestarikan lingkungan. Hal tersbut akan mengurangi penggunaan semen, sehingga akan ada pengurangan emisi $\mathrm{CO}_{2}$ karena penurunan produksi semen; 8) Dikatakan bahwa rumah yang terbuat dari ecobricks tetap hangat ketika udara di luar dingin dan tetap dingin selama musim panas. Hal tersebut akan membantu mengurangi penggunaan pendingin dan blower (Mojtaba, dkk., 2013). Manfaat paling penting yang dihasilkan dari pemanfaatan ecobricks pada anak usia dini adalah kegiatan untuk meningkatkan keterampilan motorik halus serta seni anak. 9) Penciptaan kegiatan 
dengan memanfaatkan ecobricks seperti menghias atau membentuknya menjadi mainan atau boneka dapat memengaruhi keterampilan motorik halus anak. Pada saat menghias, anak akan mewarnai dengan cat, melakukan pelekatan, dan pemotongan, sehingga keterampilan motorik halus anak akan terstimulasi begitu pula dengan aspek seninya.

Penciptaan kegiatan dengan menggunakan ecobricks melibatkan kreativitas dan imajinasi guru. Teknik yang digunakan untuk membuat ecobricks yaitu dengan memotong plastik kecil menjadi ukuran-ukuran yang lebih kecil dan memasukkannya ke dalam botol plastik bekas. Ecobricks dapat digunakan untuk membuat berbagai APE untuk anak usia dini Tindakan ini dapat mencegah limbah plastik mencemari lingkungan dan menghindari proses daur ulang oleh pemain industri yang telah terbukti kurang efektif. Proses pembuatan ecobricks selain dilakukan oleh guru juga bisa dilakukan oleh anak dan orang tuanya, bahkan kolaborasi antara ketiganya dapat pula dilakukan. Pola pikir bahwa sampah dikumpulkan oleh kelompok-kelompok tertentu, seperti pembersih kota dan pemulung tampaknya telah bergeser. Pengelolaan limbah terutama sampah plastik harus dimulai dari diri sendiri dan biasakan sejak dini. Salah satu upaya yang dapat ditempuh yaitu menggunakan sampah sebagai bahan pembuatan media pembelajaran untuk anak.

\section{METODE}

Sasaran kegiatan ini adalah guru-guru TK Marsudisiwi dan Merpati Pos Surakarta. Tujuan kegiatan ini adalah meningkatkan pengetahuan serta keterampilan guru dalam memanfaatkan ecobricks sebagai media pembelajaran khususnya sebagai bahan dasar pembuatan alat permainan edukatif (APE).

Kegiatan ini dilaksanakan dengan menggunakan beberapa metode yaitu ceramah, tanya jawab, demonstrasi, dan praktik langsung dalam membuat APE dari ecobricks. Metode ceramah bertujuan untuk memberikan pemahaman dan pengetahuan tentang ecobricks yang dapat menjadi salah satu solusi untuk mengatasi keadaan darurat sampah di Indonesia, serta memberikan berbagi informasi tentang kegiatan dan penelitian yang terkait dengan ecobricks di berbagai negara. Metode tanya jawab bertujuan untuk mengetahui pengetahuan guru tentang ecobricks. Metode demonstrasi bertujuan untuk memberikan contoh pemanfaatan ecobricks untuk membuat APE bagi anak. Metode praktik bertujuan untuk memberikan pengalaman langsung kepada guru untuk berkreasi membuat APE dengan bahan dasar ecobricks.

\section{HASIL DAN PEMBAHASAN}

Ecobricks adalah sebutan untuk botol plastik yang diisi dengan bahan nonbiologis sehingga sangat padat dan keras. Ecobricks adalah salah satu solusi yang dapat diterapkan untuk mengurangi limbah berbasis plastik dan mendaur ulangnya agar menjadi lebih bermanfaat. Pemanfaatan ecobricks antara lain sebagai bahan untuk membuat furniture, ruang, taman, dan bangunan dengan skala penuh seperti sekolah dan rumah. Ecobricks dalam kegiatan belajar mengajar dapat dimanfaatkan sebagai APE yang digunakan sebagai media pembelajaran. Karya-karya yang dihasilkan dari ecobricks dapat digunakan sebagai media pembelajaran untuk merangsang perkembangan fisik motorik halus anak, sosioemosional, kreativitas, seni, dan dapat digunakan untuk merangsang perkembangan kognitif anak.

Guru dapat mengembangkan APE dengan menggunakan ecobricks sesuai tema. Banyak produk yang bisa dihasilkan, misalnya pada tema hewan, guru bersama siswa membuat ecobricks menjadi kupu-kupu, ulat, penguin, dan lain-lain. Selain itu, pada tema transportasi, ecobricks dapat dibuat dalam bentuk pesawat terbang, kapal , roket, dan bentuk lainnya. Penggunaan ecobricks sebagai media pembelajaran juga 
dapat dikombinasikan dengan bahan lain, seperti daun kering, kertas bekas, batu, kacang, dan bahan lainnya.

Langkah-langkah dalam membuat APE dengan menggunakan ecobricks dimulai dengan mengumpulkan limbah botol minuman plastik, mencuci semuanya dengan seksama, kemudian dikeringkan. Ukuran botol disesuaikan dengan kebutuhan dan konsep APE yang dirancang. Dianjurkan untuk menggunakan botol berukuran antara 300 hingga $600 \mathrm{ml}$ agar tidak terlalu lama dalam proses pembuatannya.

Semakin besar botol, semakin lama pula waktu pembuatan dan semakin banyak plastik yang dibutuhkan untuk mengisi. Setelah itu, mengumpulkan berbagai macam kemasan plastik, seperti kemasan mie instan, minuman instan, bungkus plastik, kantong plastik dan sebagainya. Haruslah dipastikan bahwa plastik bebas dari semua jenis makanan (tertinggal di dalamnya), dalam keadaan kering dan tidak dicampur dengan bahan lain (klip, benang, kertas, dan sebagainya).
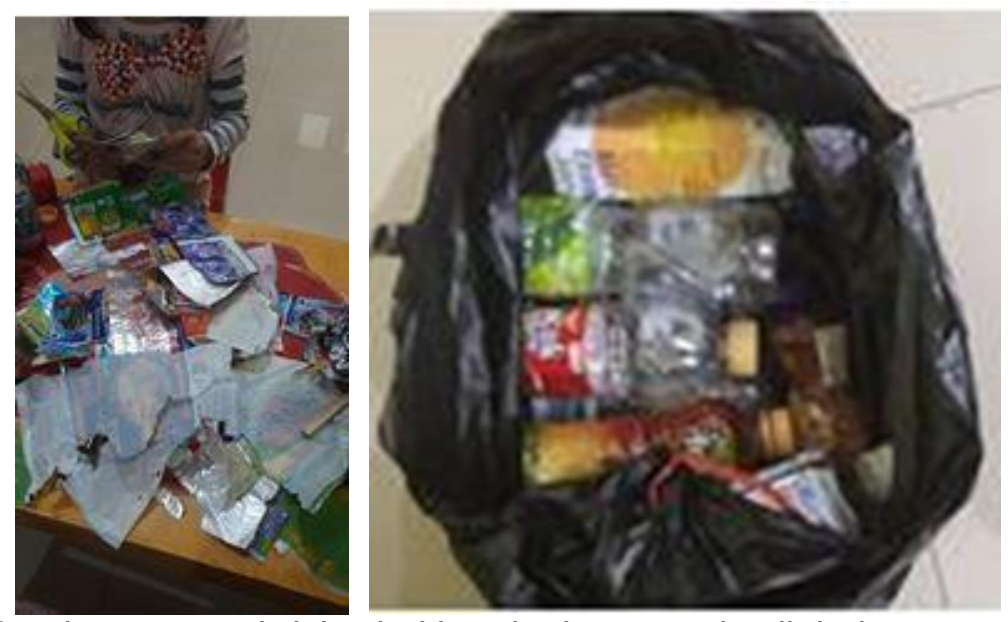

Gambar 1. Pembuatan ecobricks dari botol minuman plastik bekas yang diisi dengan bahan-bahan plastik yang lebih keci ukurannya (dalam keadaan bersih dan kering) (Sumber: Pudyaningtyas, 2019)

Langkah kedua adalah memotong plastik yang bersih dan kering, lalu memasukkan potongan plastik ke dalam botol. Tahap ini dapat merangsang kemampuan koordinasi mata dan tangan untuk melakukan gerakan motorik halus seperti memotong, mencubit, meremas dan menjepit dengan memasukkan benda ke dalam mulut botol. Bahan-bahan yang diisikan ke dalam botol tidak dapat dicampur dengan kertas, gelas, logam, benda tajam dan bahan lain selain plastik. Bahan plastik yang dimasukkan ke dalam botol plastik harus dipadatkan hingga sangat padat dan mengisi seluruh ruang di dalam botol plastik. Cara memadatkannya dengan menggunakan alat yang terbuat dari bambu atau kayu (seperti bambu atau tongkat kayu). 


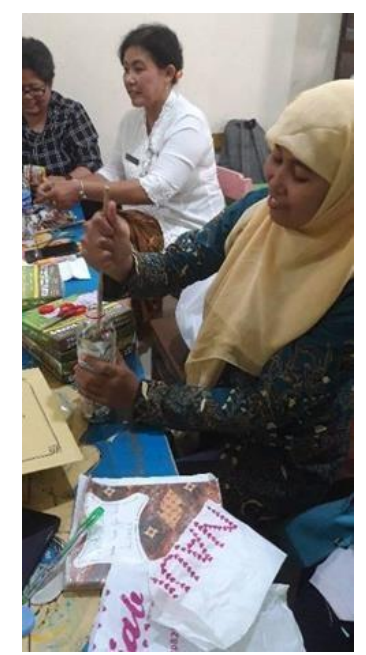

Gambar 2. Proses memasukkan potongan-potongan plastik ke dalam botol dengan menggunakan bamboo (Sumber: Pudyaningtyas, 2019)

Jika ingin membuat sesuatu dengan ecobricks, seperti membuat meja, kursi, atau benda lain, maka dapat menggunakan botol dengan ukuran yang sama, atau bahkan dari jenis dan merek yang sama, sehingga lebih mudah untuk diatur. Jika menginginkan benda yang dihasilan memiliki warna-warni yang menarik, plastik pembungkus yang diatur di dalamnya dapat diatur sedemikian rupa untuk menghasilkan warna yang diinginkan atau dapat juga dengan membungkus botol plastik dengan selotip/pita perekat berwarna atau kertas beraneka warna.
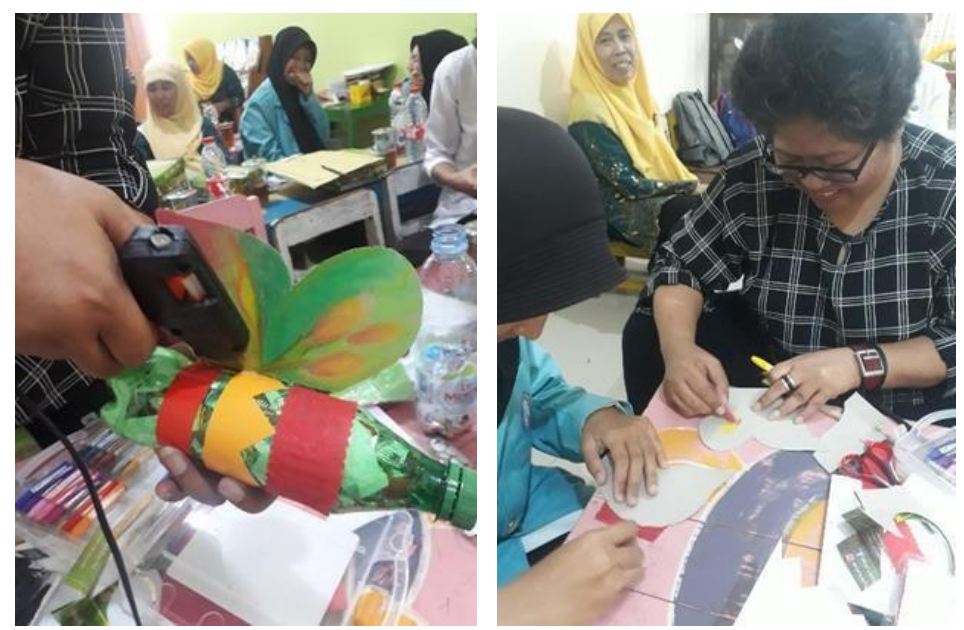

Gambar 3. Proses menghias ecobricks sesuai dengan kreativitas guru (Sumber: Palupi dan Wulandari, 2019)

Proses terakhir setelah semua botol plastik telah diisi dengan kemasan plastik sampai padat, botol-botol plastik siap untuk diatur dan digabungkan menjadi berbagai macam APE. APE yang dibentuk dapat disesuaikan dengan tema yang berlangsung di kelas seperti; mobil, boneka, menara, ulat, kupu-kupu, pesawat, roket atau bentuk lain sesuai dengan kreativitas guru. 

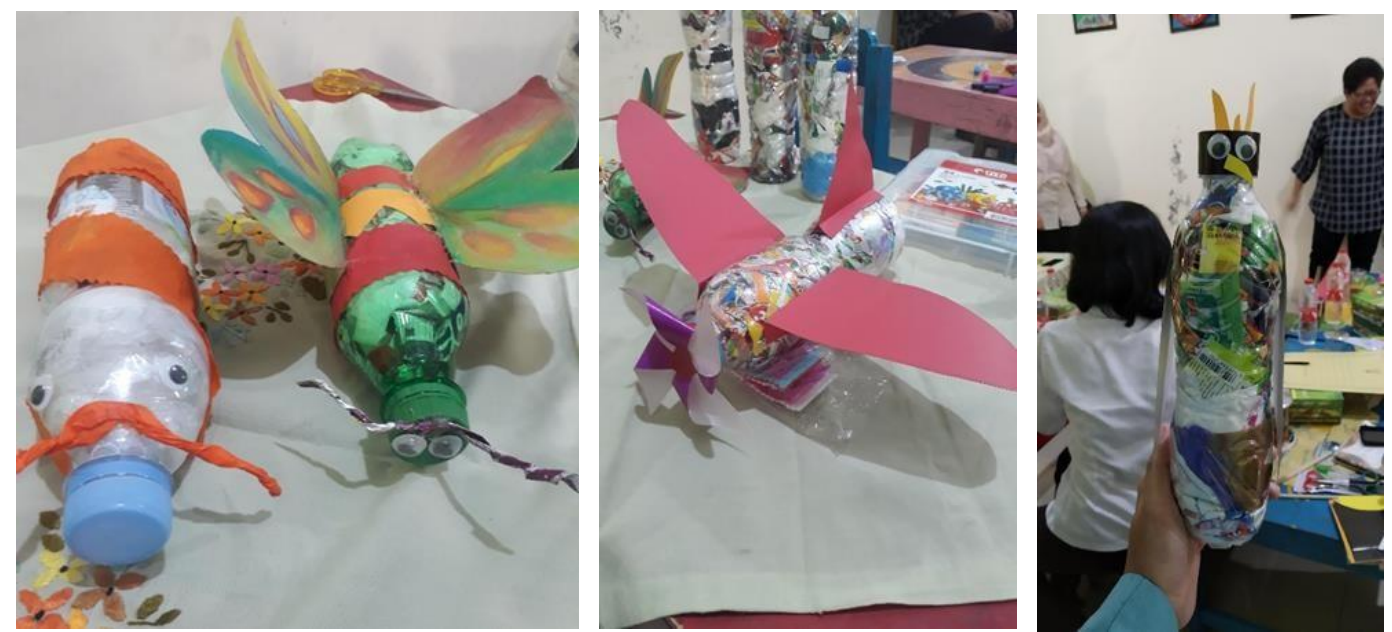

Gambar 4. Hasil APE berbahan dasar ecobricks yang berhasil diciptakan oleh guru (Sumber: Palupi dan Wulandari, 2019)

\section{KESIMPULAN}

Sampah, terutama plastik adalah salah satu masalah terbesar yang dihadapi oleh penduduk dunia saat ini. Masalah utamanya adalah limbah plastik yang tidak dapat terurai secara alami. Dibutuhkan waktu yang sangat lama untuk membersihkan sampah plastik dari bumi karena penggunaan plastik hampir tidak dapat dikendalikan. Plastik juga membuat suhu udara menjadi lebih panas, karena sifat polimer yang tidak berpori. Ecobricks adalah salah satu upaya kreatif untuk mengelola sampah plastik menjadi benda yang bermanfaat, mengurangi polusi dan racun yang disebabkan oleh sampah plastik. Fungsinya bukan untuk menghancurkan limbah plastik, melainkan untuk memperpanjang umur plastik dan mengolahnya menjadi sesuatu yang berguna, yang dapat digunakan untuk kepentingan manusia. Salah satu kegunaan ecobricks dalam pendidikan anak usia dini adalah sebagai media pembelajaran. Penggunaan ecobricks untuk media pembelajaran dalam bentuk APE perlu dicoba. Para peneliti menyarankan agar kegiatan ini dapat disosialisasikan kepada orang tua dan anak di sekolah. Selain menyenangkan, kegiatan ini juga memiliki manfaat yang beragam, terutama berkontribusi pada pengurangan sampah plastik serta diharapkan dapat merangsang banyak aspek perkembangan anak seperti perkembangan fisik terutama perkembangan motorik halus, kognitif, emosi sosial, kreativitas, dan seni.

\section{DAFTAR PUSTAKA}

Antico, F, C., Letelier, G, A., Wiener, J., \& Retamal, R, G, G. (2017). Eco-bricks: A sustainable substitute for construction materials. Article in Revista de la construcción.

Asmawati, L. (2008). Pengelolaan Kegiatan Pengembangan Sumber Belajar Untuk Anak Usia Dini. Jakarta: Depdiknas.

Badan Penelitian dan Pengembangan. (2010). Modul Pengolahan Sampah Berbasis 3R. Bandung: Kementrian Pekerjaan Umum.

Basriyanta. (2007). Memanen Sampah. Yogyakarta: Kanisius.

Beaty, J.J. (2013). Observasi Perkembangan Anak Usia Dini. Jakarta : Kencana Prenadamedia Group..

Bengkulah, M, T. (2018). Manajemen pengelolaan sampah berkelanjutan melalui inovasi "ecobrick" oleh pemerintah kota Yogyakarta. Article in Ecology.

Dadkhah, M, F, A. (2004). The impact of educational play on fine motor skills of children. Middle East Journal of Family Medicine. 6 (6). 
Departemen Kesehatan. (1987). Pedoman Bidang Studi Pembuangan Sampah. Pusat Pendidikan Tenaga Kesehatan.

Ferreira, M, E., Cruz, C., \& Pitarma, R. (2016). Teaching ecology to children of preschool education to instill environmentally friendly behavior. International Journal Of Environmental \& Science Education, 11 (12), 5619-5632.

Goyal, N., \& Manisha. (2016). Constructing structures using eco-bricks. International Journal of Recent Trends in Engineering \& Research, 2(4). 2455-1457. Hadiwiyoto,

S.. (1983). Penanganan dan Pemanfaatan Sampah. Jakarta: Yayasan Idayu.

Hamidah, M, U, W., \& Aprilina, S, R. (2016). Peningkatan motorik halus anak melalui pembuatan media daur ulang di lingkungan sekolah. Jurnal PG-PAUD Trunojoyo, 3 (1), 1-75.

Ichsan, I, Z., \& Mulyani S, W, W. (2018). Improving students' motoric skills through demonstration method in recycling plastic waste. Indonesian Journal of Biology Education, 4 (2), 189-194.

Jambeck, J, R., Geyer, R., Wileox, C., Siegler, T, R., Perryman, M., Andrady, A., Narayan, R., \& Law, K, L. (2015). Plastic waste inputs from land into the ocean. Science Research, 347, 768-770.

Kostelnik, M. J., Soderman, A. K., \& Whiren, A. P. (2017). Kurikulum Pendidikan Anak Usia Dini Berbasis Perkembangan Anak (Developmentally Appropriate Practices). Jakarta: Kencana.

Lenkiewicz, Z., \& Webster, M. (2017). Making Waste Work: A Toolkit How to turn mixed plastic waste and bottles into ecobrick $A$ step-by-step guide. UK: CIWM.

Lindsay, G, M. (2017.) Art is experience: an exploration of the visual arts beliefs and pedagogy of australian early childhood educators. Doctor of Philosophy thesis, School of Education, University of Wollongong, htps://ro.uow.edu.au/theses $1 / 170$

Maier, R., \& Angway, I. (2015). Panduan Visi Eco-Brick. Ecobrick.org.

Mohamed, R, M, S, R., Al-Gheethi, A, A., \& Yaakob, M, A. (2017). Recycling of solid wastes at kindergartens centers. Songklanakarin J. Sci. Technol, 39 (1), 6975.

Peraturan Menteri Pendidikan dan Kebudayaan Republik Indonesia Nomor 137 Tahun 2014 tentang Standar Nasional Pendidikan Anak Usia Dini.

Sujarwo, Tristanti, \& Widyaningsih. (2014). Pengelolaan Sampah Organik dan Anorganik. Yogyakarta: Pendidikan Luar Sekolah Fakultas IImu Pendidikan Universitas Negeri Yogyakarta.

Suryani, Reno. (2014). Kreasi Kertas Bekas. Yogyakarta: Arcitra.

Warash, B, G. (2004). Paper dolls: back to basics, with a contemporary twist. Dimensions Of Early Childhood, 32 (1).

Muyen, Z., Barna, T., \& Hoque, M. (2016). Strength properties of plastic bottle bricks and their suitability as construction materials in Bangladesh. Progressive Agriculture, 27(3), 362-368. 